\title{
Prevalence and Impact of Migraine among University Students in Bangladesh: Findings from a Cross-sectional Survey
}

\section{Md. Abdur Rafi}

Rajshahi Medical College

Md. Saiful Islam

Jahangirnagar University

M. Tasdik Hasan

University of Liverpool

Md. Golam Hossain ( $\nabla$ hossain95@yahoo.com )

University of Rajshahi

Research article

Keywords: Migraine, ID MigraineTM, HIT-6, university students, Bangladesh

Posted Date: December 9th, 2020

DOl: https://doi.org/10.21203/rs.3.rs-120597/v1

License: (c) (i) This work is licensed under a Creative Commons Attribution 4.0 International License.

Read Full License

Version of Record: A version of this preprint was published at BMC Neurology on February 26th, 2022.

See the published version at https://doi.org/10.1186/s12883-022-02594-5. 


\section{Abstract}

Background: Migraine is one of the main causes of long-term morbidity, and it is one of the major contributors of all types of headaches in worldwide. Despite its disruptive effect, it is frequently underdiagnosed and undertreated in Bangladesh. The aim of the present study was to determine the prevalence of migraines and its impact on daily life of university students in Bangladesh.

Methods: This cross-sectional study was conducted among 2,352 students of Rajshahi University and Jahangirnagar University during March 2020 through a self-administered online survey. ID Migraine ${ }^{\mathrm{TM}}$ scale and HIT-6 scale were used to screen migraine and its impact respectively. Frequency distribution, and Chi-square test, t-test along with multiple logistic regressions model were used to determine the prevalence and associated factors of migraine respectively.

Results: The overall prevalence of migraine among the participants was $21.4 \%$. The prevalence was higher among females (29\%) than males (12\%). A multivariable logistic regression model provided the following eight risk factors of migraine: (i) gender ( $p<0.01)$, (ii) family income $(p<0.01)$, (iii) marital status $(p<0.01)$, (iv) infrequent exercise $(p<0.01)$, (v) family history of headache $(p<0.01)$, (vi) high screen time $(p<0.05)$, (vii) depressive symptoms $(p<0.05)$ and (viii) anxiety disorder $(p<0.01)$. More than two-thirds of the migraineurs reported more than five attacks during the past month with moderate to severe intense headache. Stress was the most reported trigger of migraine among university students (71\%) followed by irregular sleep (47\%), academic pressure (33\%), and external noise (28\%). Almost $37 \%$ of the participants who had migraines reported that headache caused severe impact in their day to day life.

Conclusions: The prevalence of migraine among university students of Bangladesh is alarmingly high. Frequent migraine attacks and severe intensity of headache cause a substantial level of impact among the sufferers. Cautious avoidance of the triggering factors through appropriate interventions and prophylactic medication can mitigate the negative impact of migraine as well as improve the quality of life.

\section{Background}

Headache disorder is one of the main causes of long-term morbidity worldwide. It is listed as the second leading cause of years lived with disability for the last three decades according to the Global Burden of Disease Study (1). Migraine is one of the major contributors of all types of headaches with a lifetime prevalence of 14 to $16 \%$ around the world (2). It is often associated with impaired social and professional life and reduced productivity, making it responsible for roughly $3 \%$ of disability making it the eighth most burdensome disease $(2,3)$.

A wide range of factors including stress, noise and sound, fatigue, fasting, sleep disorder, alcohol drinking, etc. are associated with the precipitation of migraine (5). These triggering factors notably educational stress and irregular sleep are more prevalent among young adults compared to other age groups, especially university students, which have made them vulnerable to migraines. It is reported that 
almost $10-18 \%$ of university students suffer from migraine worldwide (6). This high prevalence of migraine impairs the academic performance of the students and also decrease the quality of life of the sufferers $(7,8)$.

Regardless of its disruptive effect, migraine is frequently underdiagnosed and undertreated in Bangladesh. There is scarcity of evidence reporting the prevalence and effect of migraine among university students of Bangladesh. A study including a small sample reported that the prevalence of migraines as $17.4 \%$ among medical students suffering from irritable bowel syndrome (9). However, the study did not evaluate the risk factors and the effect of migraine on their life events. University students are asset of a particular country, special attention is paid to university students considering their potential contribution to the nation. Due to their unique role in the country, it is important to understand the prevalence and identify the risk factors of migraine as well as its effect on their daily life for taking further preventive measures.

Therefore, the present study aims to determine the prevalence and risk factors of migraines among the university students of Bangladesh as well as the effect of this disease on their daily life.

\section{Methods}

\section{Study design and setting:}

This was a cross-sectional study conducted among the two selected universities students (i.e., University of Rajshahi and Jahangirnagar University) during March 2020 through an online survey. The University of Rajshahi and Jahangirnagar University is the second and fourth largest universities in Bangladesh respectively, with students coming from the different parts of the country. A total number of 55276 students are studying in these two universities (38495 in University of Rajshahi, and 16781 in Jahangirnagar University).

\section{Sample size calculation and sampling method:}

The sample size was calculated from the prevalence estimate using the formula:

\section{$\mathrm{n}=\frac{\mathrm{z}^{2} \mathrm{pq}}{\mathrm{d}^{2}}$}

where, $n=$ number of the samples; $z=1.96$ for $95 \%$ confidence interval $(\mathrm{Cl}), \mathrm{p}=$ "best guess" for prevalence and $d=$ precision of the prevalence estimate. We did not find any existing data on the prevalence of migraine among the university students of Bangladesh. However, a previous study from the neighboring country India reported the prevalence as $14.12 \%$ (10), which was considered as $p$ (best guess) value ( $p=0.1412)$ for calculating sample size for the present study, and the formula provided that 
2337 sample would be the required size. Assuming a 10\% non-response rate, a total of 2600 university students were approached. The convenient sampling method was used to include the participants in this study as those who had the social media id and personal relation with the recruited volunteers had the chances of enrollment in the study.

Data collection procedure: A self-administered online survey form created in Google forms were used to collect data from the participants. The survey link was posted in a regular interval of one week in the internal social media groups of the university students and an open request was placed by the team of investigators to fill-up the form. Also, 20 volunteers from different departments of these universities were employed to circulate the survey link among their student networks, in addition to regular posting in the above-mentioned social media groups. They were instructed to be inclusive, open, and circulate it periodically for maximum reach. Login with email and providing student ID number was mandatory for limiting single response. Email addresses of the participants were collected upon proper clarification and informed consent for the reliability of the data. The study was conducted following the Checklist for Reporting Results of Internet ESurveys (CHERRIES) guidelines (11).

\section{Data collection instruments:}

The survey questionnaire comprised of four parts: (i) socio-demographics, lifestyle and behavioral factors related data, (ii) headache-related data, (iii) impact of headache, if migraine was present using the Headache Impact Test (HIT-6), and (iv) presence of anxiety and depressive symptoms using two psychometric scales (the GAD-7 for assessing anxiety disorder and the PHQ-9 for assessing depressive symptoms). As the ID Migraine ${ }^{\mathrm{TM}}$ and HIT-6 scales were not used before among Bangladeshi population, these were not validated in Bangla. We have used back translation method for translating the tools after proper consent from the developers under supervision of a team of three consultant neurologists of the Department of Neuromedicine of RMCH (Rajshahi Medical College \& Hospital). A pretest of the questionnaire was done in the Department of Neuromedicine od $\mathrm{RMCH}$ among 30 diagnosed migraine patients by a consultant neurologist.

\section{Part 1: Socio-demographics, lifestyle and behavioral factors:}

Socio-demographic information was collected during the survey by asking questions concerning age, gender, study year, monthly family income, marital status, height, and weight. Lifestyle and behavioral factors included fast food intake (frequency per week), amount of physical exercising (days per week for at least 30 minutes a day), smoking habits (yes/no), alcohol intake (yes/no), substance abuse (yes/no), and sleep quality measured by the Pittsburgh sleep quality index (PSQI) which is an appropriate screening tool for measuring sleep dysfunction in both clinical and non-clinical samples. The PSQI score was categorized as poor (PSQI score >5) and good (PSQI score £5) (12). 


\section{Part 2: Headache related data:}

Participants were initially evaluated by the question "Did you have two or more headaches in the last 3 months?" Those who responded 'yes" were considered as the subjects with potentially troublesome headaches and further screened using the ID Migraine ${ }^{\mathrm{TM}}$ test. The ID-Migraine ${ }^{\mathrm{TM}}$ test is a three-item selfadministered screening tool, developed by Lipton et al. (2003) (13). It consists of three questions regarding problems related to migraines over the last three months: 1. Did you feel nauseated or sick in your stomach with your headaches? 2. Did light bother you when you had a headache (a lot more than when you do not have headaches)? and 3. Did your headache limit your ability to work, study or do what you needed to do for at least 1 day? A test-diagnosis of migraine headache is made by at least two positive responses. ID Migraine ${ }^{\mathrm{TM}}$ has been validated using the International Classification of Headache Disorders (ICHD) criteria in different studies with a pooled sensitivity of 0.84 and a specificity of 0.76 (14).

Headache related data were collected from the participants who were screened as positive for migraine. These included intensity of headache (measured on a four-point scale where $0=$ no headache; $1=$ mild headache; 2 = moderate headache; 3 = severe headache recommended for use in migraine research by the International Headache Society) (15), frequency of headache during the past month, associated symptoms of headache, characteristic of headache (unilateral, bilateral, pulsating, and throbbing), frequency of analgesic use during the past month, frequency of healthcare facility visit during past 12 months, migraine triggers, and family history of migraine.

\section{Part 3: Impact of headache:}

Headache Impact Test (HIT-6) was used to measure the impact of migraine headaches among the ID Migraine ${ }^{\mathrm{TM}}$ positive participants. The HIT-6 is a brief and easy to use instrument, developed by Kosinski et al. (2003) (16) to measure the adverse headache impact and to use in screening and monitoring patients with headaches in both clinical practice and clinical research. It consists of six items regarding problems related to headache (i.e., When you have headaches, how often is the pain severe?) with a five-point Likert scale ranging from 6 (Never) to 13 (Always). The total score was obtained by the summating raw score from each contract ranging from 36 to 78, with greater scores indicating a severe impact. In present study, the headache impact severity was categorized into four classes based on total sores of HIT-6: little or no disability ( $\leq 49)$, mild disability $(50-55)$, moderate disability (56-59), and disability $(\geq 60)$. This scale is suggested as a reliable and valid tool for measuring headache impact in migraine (17).

\section{Part 4: Anxiety and depressive symptoms:}

Patient Health Questionnaire (PHQ-9: The PHQ-9 is one of the most psychometrically sound and robust screening tools, developed by Spitzer et al. (1999) (18) which is one the most widely used instruments for 
assessing depressive disorder globally including Bangladesh $(19,20)$. This scale consists of nine items regarding problems related to depression symptomatology over the past two weeks (e.g., "Thoughts that you would be better off dead, or of hurting yourself in some way?") with a four-point Likert scale ranging from 0 (Not at all) to 3 (Nearly every day). The total score was obtained by the summating raw score from each contract ranging from 0 to 27 . In the present study, those scoring moderate to severe $(\geq 10)$ were classed as having depressive symptoms (21).

Generalized Anxiety Disorder (GAD-7): The GAD-7 is one of the most psychometrically sound and robust screening tools, developed by Spitzer et al. (2006) (22) and used in different countries including Bangladesh for assessing anxiety disorder $(23,24)$. The scale comprises seven items regarding problems related to anxiety symptomatology over the past two weeks (e.g., "Feeling afraid as if something awful might happen?") with a four-point Likert scale ranging from 0 (Not at all) to 3 (Nearly every day). The total score was obtained by the summating raw score from each contract ranging from 0 to 21 . In the present study, those scoring moderate to extremely severe $(\geq 10)$ were classified as having anxiety disorder positive (22).

\section{Statistical analysis:}

Statistical analysis was conducted using SPSS version 24.0. Descriptive statistics was performed for categorical variables (i.e., frequency and percentage), and for continuous variables (i.e., mean and standard deviation). Chi-square test and t-test were used in case of categorical variables and continuous variables, respectively to investigate the relationship between dependent and independent variables. Binary multiple logistic regressions were performed with a $95 \%$ confidence interval to determine the significant associations between categorical dependent and independent variables. Multicollinearity problems among independent variables in multiple logistic model was checked by standard error (SE) suggested by Chan (25). The association of variables was considered statistically significant if the twosided $p$-value was less than 0.05 .

\section{Results}

\section{Characteristics of the participants:}

A total of 2,352 university students participated in the study. Their mean age was $21.9(S D=2.3)$ years. More than half of them (56\%) were female. Almost $47 \%$ of the participants were from middle income families. BMI of $63 \%$ participants was within a normal range $\left(18.5-24.9 \mathrm{~kg} / \mathrm{m}^{2}\right)$. Among the participants, $25 \%, 19 \%$ and $11 \%$ were smokers, alcoholic and substance abusers, respectively. More than $69 \%$ of the participants reported poor sleep quality. The prevalence of anxiety and depressive symptoms were $29 \%$ and $42 \%$, respectively (Table 1 ). 
Table 1

Socio-demographic and lifestyle related characteristics of the participants $(n=2352)$

\begin{tabular}{|c|c|c|c|c|}
\hline Characteristics & $\begin{array}{l}\text { Total } \\
\text { N (\%) }\end{array}$ & $\begin{array}{l}\text { Migraine } \\
\mathrm{N}(\%)\end{array}$ & $\begin{array}{l}\text { No } \\
\text { migraine N } \\
(\%)\end{array}$ & $\begin{array}{l}\text { p- } \\
\text { value }\end{array}$ \\
\hline Age (Mean, SD) & $\begin{array}{l}21.9 \\
(2.3)\end{array}$ & $\begin{array}{l}21.7 \\
(2.2)\end{array}$ & $21.9(2.3)$ & 0.051 \\
\hline \multicolumn{5}{|l|}{ Sex } \\
\hline Female & $\begin{array}{l}1313 \\
(55.8)\end{array}$ & $\begin{array}{l}378 \\
(28.8)\end{array}$ & $935(71.2)$ & $<0.001$ \\
\hline Male & $\begin{array}{l}1039 \\
(44.2)\end{array}$ & $\begin{array}{l}125 \\
(12.0)\end{array}$ & $914(88.0)$ & \\
\hline \multicolumn{5}{|l|}{ Year of study } \\
\hline $1^{\text {st }}$ & $\begin{array}{l}621 \\
(26.4)\end{array}$ & $\begin{array}{l}196 \\
(31.6)\end{array}$ & $425(68.4)$ & $<0.001$ \\
\hline $2^{\text {nd }}$ & $\begin{array}{l}534 \\
(22.7)\end{array}$ & $\begin{array}{l}78 \\
(14.6)\end{array}$ & $456(85.4)$ & \\
\hline $3^{\text {rd }}$ & $\begin{array}{l}511 \\
(21.7)\end{array}$ & $\begin{array}{l}90 \\
(17.6)\end{array}$ & $421(82.4)$ & \\
\hline $4^{\text {th }}$ & $\begin{array}{l}403 \\
(17.1)\end{array}$ & $\begin{array}{l}77 \\
(19.1)\end{array}$ & $326(80.9)$ & \\
\hline $5^{\text {th }} /$ Masters & $\begin{array}{l}283 \\
(12.0)\end{array}$ & $\begin{array}{l}62 \\
(21.9)\end{array}$ & $221(78.1)$ & \\
\hline \multicolumn{5}{|l|}{ Family income } \\
\hline Low (<BDT 15000) & $\begin{array}{l}458 \\
(19.5)\end{array}$ & $\begin{array}{l}80 \\
(17.5)\end{array}$ & $378(82.5)$ & $<0.001$ \\
\hline Middle (BDT 15000-30000) & $\begin{array}{l}1098 \\
(46.7)\end{array}$ & $\begin{array}{l}203 \\
(18.5)\end{array}$ & $895(81.5)$ & \\
\hline High (BDT >30000) & $\begin{array}{l}796 \\
(33.8)\end{array}$ & $\begin{array}{l}220 \\
(27.6)\end{array}$ & $576(72.4)$ & \\
\hline \multicolumn{5}{|l|}{ Marital status } \\
\hline Married & $\begin{array}{l}261 \\
(11.1)\end{array}$ & $\begin{array}{l}83 \\
(31.8)\end{array}$ & $178(68.2)$ & $<0.001$ \\
\hline Unmarried & $\begin{array}{l}2091 \\
(88.9)\end{array}$ & $\begin{array}{l}420 \\
(20.1)\end{array}$ & $1671(79.9)$ & \\
\hline \multicolumn{5}{|l|}{ BMI } \\
\hline Overweight ( $\geq 25 \mathrm{~kg} / \mathrm{m}^{2}$ ) & $\begin{array}{l}434 \\
(18.5)\end{array}$ & $\begin{array}{l}85 \\
(19.6)\end{array}$ & $349(80.4)$ & 0.560 \\
\hline
\end{tabular}




\begin{tabular}{|c|c|c|c|c|}
\hline Normal $\left(18.5-24.9 \mathrm{~kg} / \mathrm{m}^{2}\right)$ & $\begin{array}{l}1481 \\
(62.9)\end{array}$ & $\begin{array}{l}320 \\
(21.6)\end{array}$ & $1161(78.4)$ & \\
\hline Underweight $\left(<18.5 \mathrm{~kg} / \mathrm{m}^{2}\right)$ & $\begin{array}{l}437 \\
(18.6)\end{array}$ & $\begin{array}{l}98 \\
(22.4)\end{array}$ & $339(77.6)$ & \\
\hline \multicolumn{5}{|c|}{ Frequency of fast-food intake per week } \\
\hline More than 3 times & $\begin{array}{l}217 \\
(9.2)\end{array}$ & $\begin{array}{l}45 \\
(20.7)\end{array}$ & $172(79.3)$ & 0.840 \\
\hline $1-2$ times & $\begin{array}{l}778 \\
(33.1)\end{array}$ & $\begin{array}{l}162 \\
(20.8)\end{array}$ & $616(79.2)$ & \\
\hline Less than once & $\begin{array}{l}1357 \\
(57.7)\end{array}$ & $\begin{array}{l}296 \\
(21.8)\end{array}$ & $1061(78.2)$ & \\
\hline \multicolumn{5}{|c|}{$\begin{array}{l}\text { Frequency of exercise per week (at least } 30 \text { minutes } \\
\text { daily) }\end{array}$} \\
\hline More than 3 times & $\begin{array}{l}423 \\
(18.0)\end{array}$ & $\begin{array}{l}83 \\
(19.6)\end{array}$ & $340(80.4)$ & 0.014 \\
\hline $1-2$ times & $\begin{array}{l}446 \\
(19.0)\end{array}$ & $\begin{array}{l}118 \\
(26.5)\end{array}$ & $328(73.5)$ & \\
\hline Less than once & $\begin{array}{l}1483 \\
(63.1)\end{array}$ & $\begin{array}{l}302 \\
(20.4)\end{array}$ & $1181(79.6)$ & \\
\hline \multicolumn{5}{|l|}{ Screen time (daily) } \\
\hline$>12$ hours & $\begin{array}{l}201 \\
(8.5)\end{array}$ & $\begin{array}{l}51 \\
(25.4)\end{array}$ & $150(74.6)$ & $<0.001$ \\
\hline $6-12$ hours & $\begin{array}{l}811 \\
(34.5)\end{array}$ & $\begin{array}{l}223 \\
(27.5)\end{array}$ & $588(72.5)$ & \\
\hline 2-6 hours & $\begin{array}{l}1052 \\
(44.7)\end{array}$ & $\begin{array}{l}176 \\
(16.7)\end{array}$ & $876(83.3)$ & \\
\hline$<2$ hours & $\begin{array}{l}288 \\
(12.2)\end{array}$ & $\begin{array}{l}53 \\
(18.4)\end{array}$ & $235(81.6)$ & \\
\hline \multicolumn{5}{|l|}{ Smoking } \\
\hline Yes & $\begin{array}{l}591 \\
(25.1)\end{array}$ & $\begin{array}{l}115 \\
(19.5)\end{array}$ & $476(80.5)$ & 0.187 \\
\hline No & $\begin{array}{l}1761 \\
(74.9)\end{array}$ & $\begin{array}{l}388 \\
(22.0)\end{array}$ & $1373(78.0)$ & \\
\hline \multicolumn{5}{|l|}{ Alcohol intake } \\
\hline Yes & $\begin{array}{l}441 \\
(18.8)\end{array}$ & $\begin{array}{l}103 \\
(23.4)\end{array}$ & $338(76.6)$ & 0.263 \\
\hline No & $\begin{array}{l}1911 \\
(81.3)\end{array}$ & $\begin{array}{l}400 \\
(20.9)\end{array}$ & $1511(79.1)$ & \\
\hline
\end{tabular}


Substance abuse (e.g. cannabis, heroine, marijuana, amphetamines etc.)

\begin{tabular}{|c|c|c|c|c|}
\hline Yes & $\begin{array}{l}262 \\
(11.1)\end{array}$ & $\begin{array}{l}68 \\
(26.0)\end{array}$ & $194(74.0)$ & 0.056 \\
\hline No & $\begin{array}{l}2090 \\
(88.9)\end{array}$ & $\begin{array}{l}435 \\
(20.8)\end{array}$ & $1655(79.2)$ & \\
\hline \multicolumn{5}{|c|}{ Family history of chronic headache } \\
\hline Yes & $\begin{array}{l}993 \\
(42.2)\end{array}$ & $\begin{array}{l}303 \\
(30.5)\end{array}$ & $690(69.5)$ & $<0.001$ \\
\hline No & $\begin{array}{l}1359 \\
(57.8)\end{array}$ & $\begin{array}{l}200 \\
(14.7)\end{array}$ & $1159(85.3)$ & \\
\hline \multicolumn{5}{|l|}{ Sleep quality } \\
\hline Poor (PSQI score >5) & $\begin{array}{l}1627 \\
(69.2)\end{array}$ & $\begin{array}{l}388 \\
(23.8)\end{array}$ & $1239(76.2)$ & $<0.001$ \\
\hline Good (PSQI score $£ 5$ ) & $\begin{array}{l}728 \\
(31.0)\end{array}$ & $\begin{array}{l}115 \\
(15.8)\end{array}$ & $613(84.2)$ & \\
\hline \multicolumn{5}{|l|}{ Anxiety } \\
\hline Yes (GAD-7 score $\geq 10$ ) & $\begin{array}{l}686 \\
(29.2)\end{array}$ & $\begin{array}{l}235 \\
(34.3)\end{array}$ & $451(65.7)$ & $<0.001$ \\
\hline No (GAD-7 score < 10) & $\begin{array}{l}1666 \\
(70.8)\end{array}$ & $\begin{array}{l}268 \\
(16.1)\end{array}$ & $1398(83.9)$ & \\
\hline \multicolumn{5}{|l|}{ Depression } \\
\hline Yes (PHQ-9 score $\geq 10$ ) & $\begin{array}{l}984 \\
(41.8)\end{array}$ & $\begin{array}{l}282 \\
(28.7)\end{array}$ & 702 (71.3) & $<0.001$ \\
\hline No (PHQ-9 score < 10) & $\begin{array}{l}1368 \\
(58.2)\end{array}$ & $\begin{array}{l}221 \\
(16.2)\end{array}$ & $1147(83.8)$ & \\
\hline
\end{tabular}

\section{Prevalence of migraine:}

The overall prevalence of migraine among the participants was $21.4 \%$. The prevalence was higher among females vs. males ( $29 \%$ vs. $12 \%$ ), participants from $1^{\text {st }}$ year vs. $2^{\text {nd }}$ year $(32 \%$ vs. $15 \%)$, married vs. unmarried ( $32 \%$ vs. $20 \%$ ), and participants from high-income families $(27.6 \%$ vs. $18.5 \%$ in middle and $17.5 \%$ in low-income families). Moreover, the prevalence of migraine was higher among the participants who reported higher vs. lower daily screen time ( $27.5 \%$ for $>6$ hours vs. $16.7 \%$ for $<6$ hours), having family history of headache vs. those who hadn't ( $30.5 \%$ vs. $14.7 \%)$, poor vs. good sleep quality ( $24 \%$ vs. $16 \%)$, having with vs. without considerable anxiety (34\% vs. $16 \%)$ and having with vs. without considerable depressive symptoms (29\% vs. $16 \%$ ) (Table 1$)$. 
Only the significant factors provided by Chi-square were used as independent variables in multiple logistic regression models, and the magnitude value of SE of each variable was less than 0.50 , no evidence of multicollinearity problems among our selected independent variables. After controlling the effect of other variables, the model demonstrated that predictors of suffering from migraine included female sex (aOR 2.53, 95\% Cl: 1.97-3.24; $\mathrm{p}<0.01$ ), high family income (aOR 0.70, 95\% Cl: 0.51 -

$0.96 ; p<0.05$ for low income and aOR $0.74,95 \% \mathrm{Cl}$ : 0.58-0.95; $\mathrm{p}<0.05$ for middle income), being married (aOR 1.54, 95\% Cl: 1.12-2.11; $p<0.01$ ), infrequent exercise (aOR 1.51, 95\% Cl: 1.14-1.98; $p<0.01$ ), high screen time (aOR 1.47, 95\% Cl: 1.02-2.12; $\mathrm{p}<0.05)$ and family history of headache (aOR $2.29,95 \% \mathrm{Cl}: 1.83-$ 2.85; $p<0.01$ ). Moreover, those who reported anxiety had 2.35 times higher risk of suffering from migraine (aOR 2.35, 95\% Cl: 1.77-3.12; $\mathrm{p}<0.01$ ), while those who reported depressive symptoms had 1.35 times higher risk (aOR1.35, 95\% Cl: 1.02-1.79; p<0.05) (Table 2). 
Table 2

Predictors of migraine among the participants in logistic regression model $(n=2352)$

\begin{tabular}{|c|c|c|}
\hline Characteristics & aOR $(95 \% \mathrm{Cl})$ & p-value \\
\hline \multicolumn{3}{|l|}{ Sex } \\
\hline Female & $2.53(1.97-3.24)$ & $<0.001$ \\
\hline Male & Ref. & \\
\hline \multicolumn{3}{|l|}{ Year of study } \\
\hline $1^{\text {st }}$ & $1.46(0.99-2.12)$ & 0.051 \\
\hline $2^{\text {nd }}$ & $0.63(0.42-1.05$ & 0.058 \\
\hline $3^{\text {rd }}$ & $0.84(0.56-1.25)$ & 0.396 \\
\hline $4^{\text {th }}$ & $0.98(0.65-1.48)$ & 0.946 \\
\hline $5^{\text {th }} /$ Masters & Ref. & \\
\hline \multicolumn{3}{|l|}{ Family income } \\
\hline Low (<BDT 15000) & $0.70(0.51-0.96)$ & 0.031 \\
\hline Middle (BDT 15000-30000) & $0.74(0.58-0.95)$ & 0.018 \\
\hline High (BDT >30000) & Ref. & \\
\hline \multicolumn{3}{|l|}{ Marital status } \\
\hline Married & $1.54(1.12-2.11)$ & 0.007 \\
\hline Unmarried & Ref. & \\
\hline \multicolumn{3}{|c|}{ Frequency of exercise per week (at least 30 minutes daily) } \\
\hline More than 3 times & $1.19(0.88-1.61)$ & 0.251 \\
\hline 1-2 times & $1.51(1.14-1.98)$ & 0.003 \\
\hline Less than once & Ref. & \\
\hline \multicolumn{3}{|l|}{ Screen time (daily) } \\
\hline$>12$ hours & $1.33(0.82-2.15)$ & 0.244 \\
\hline $6-12$ hours & $1.47(1.02-2.12)$ & 0.041 \\
\hline 2-6 hours & $0.88(0.61-1.28)$ & 0.525 \\
\hline$<2$ hours & Ref. & \\
\hline Family history of headache & & \\
\hline
\end{tabular}




\begin{tabular}{|lll|}
\hline Yes & $2.29(1.83-2.85)$ & $<0.001$ \\
\hline Sleep quality & Ref. & \\
\hline Poor (PSQI score $>5)$ & & \\
\hline Good (PSQI score $<5)$ & $1.24(0.95-1.62)$ & 0.100 \\
Anxiety & Ref. & \\
Yes (GAD-7 score $>10)$ & & \\
\hline No (GAD-7 score $<10)$ & $2.35(1.77-3.12)$ & $<0.001$ \\
\hline Depression & Ref. & \\
\hline Yes (PHQ-9 score $>10)$ & & \\
\hline No (PHQ-9 score $<10)$ & $1.35(1.02-1.79)$ & 0.035 \\
\hline
\end{tabular}

\section{Characteristics of migraine:}

Almost $68 \%$ of the participants who had migraines reported the intensity of their headache as moderate to severe, and almost $88 \%$ of them had more than five attacks during the past month. Nausea was the most common symptoms associated with migraine (81\%) followed by photophobia (67\%) and vomiting (52.5\%). More than $77 \%$ of the migraineurs had unilateral headache and pulsating in nature $(85 \%)$.

Almost $57.5 \%$ of the migraineurs had used analgesic more than five times during the past month and almost $42 \%$ had visited healthcare facilities due to their headache at least once during the last 12 months. Stress was the most commonly reported trigger of migraine among the participants $(71 \%)$ followed by irregular sleep (47\%), much reading (33\%), noise $(28 \%)$ and overuse of electronic device (25\%) (Table 3). 
Table 3

Headache related characteristics among the participants with migraine $(n=503)$

\begin{tabular}{|c|c|c|}
\hline Characteristics & $\mathbf{N}$ & $\%$ \\
\hline \multicolumn{3}{|c|}{ Intensity of headache } \\
\hline Mild & 163 & 32.4 \\
\hline Moderate & 185 & 36.8 \\
\hline Severe & 155 & 30.8 \\
\hline \multicolumn{3}{|c|}{ Frequency of headache during past month } \\
\hline $0-5$ & 111 & 22.1 \\
\hline $6-10$ & 184 & 36.6 \\
\hline $11-15$ & 137 & 27.2 \\
\hline$>15$ & 71 & 14.1 \\
\hline \multicolumn{3}{|c|}{ Associated symptoms } \\
\hline Nausea & 407 & 80.9 \\
\hline Vomiting & 264 & 52.5 \\
\hline Photophobia & 337 & 67.0 \\
\hline \multicolumn{3}{|c|}{ Characteristic of headache } \\
\hline Unilateral & 389 & 77.3 \\
\hline Bilateral & 114 & 22.7 \\
\hline Pulsating & 428 & 85.1 \\
\hline Throbbing & 75 & 14.9 \\
\hline \multicolumn{3}{|c|}{ Frequency of analgesic use during the past month } \\
\hline $0-5$ & 214 & 42.5 \\
\hline $6-10$ & 155 & 30.8 \\
\hline $11-15$ & 99 & 19.7 \\
\hline$>15$ & 35 & 7.0 \\
\hline \multicolumn{3}{|c|}{ Frequency of healthcare facility visit during the past 12 months } \\
\hline Never & 293 & 58.3 \\
\hline Once & 110 & 21.9 \\
\hline Twice & 72 & 14.3 \\
\hline
\end{tabular}




\begin{tabular}{|l|cc|}
\hline 3 times & 17 & 3.4 \\
\hline$>3$ times & 11 & 2.2 \\
\hline Migraine triggers (as reported by the participants in open ended question) & & \\
\hline Stress & 356 & 70.8 \\
\hline Irregular sleep & 237 & 47.1 \\
\hline Academic pressure & 167 & 33.2 \\
\hline External noise (e.g. loudspeaker, crowd etc.) & 142 & 28.2 \\
\hline Electronic device use (e.g. laptop, mobile phones? & 124 & 24.7 \\
\hline Physical activity & 89 & 17.7 \\
\hline Exposure to sun & 74 & 14.7 \\
\hline Menstruation in female & 63 & 12.5 \\
\hline Smoking & 46 & 9.1 \\
\hline Specific food or drink (e.g. coffee, tea, chocolates etc. ) & 38 & 7.6 \\
\hline Others & 56 & 11.1 \\
\hline
\end{tabular}

\section{Impact of migraine:}

Almost $37 \%$ of the participants who had migraines reported that headache caused severe impact in their day to day activities (HIT-6 score $\geq 60$ ), while mild and moderate levels of impact due to migraines were reported as $13 \%$ and $16 \%$ respectively. Only $34 \%$ of the migraineurs reported little or no impact due to migraine (HIT-6 score $\leq 49$ ) (Figure1).

\section{Discussion}

The present study was one of the primary attempts to determine the prevalence of migraine among the university students of Bangladesh. According to our findings, overall $21.4 \%$ of the university students were suffering from migraines, as screened by the self-reported ID Migraine ${ }^{\mathrm{TM}}$ tool. This prevalence was comparatively higher than the prevalence among the university students of neighboring India $(14.12 \%)$ (10). A meta-analysis of 56 studies including 34904 university students reported that the prevalence of migraine ranges between $2.4 \%$ and $48.5 \%$ in different countries of the world. The pooled prevalence of migraine in university students was $16.1 \%(95 \% \mathrm{Cl} 13.6 \%-18.9 \%)(6)$.

The prevalence of migraine varies a lot according to the applied diagnostic criteria. For example, according to ICHD-1 criteria, the prevalence of migraine was $12.7 \%$, according to ICHD-2 criteria it was $17.5 \%$, while according to ICHD-3 criteria it was $29.2 \%$ (6). Similarly, our used screening tool, ID 
Migraine $^{\mathrm{TM}}$, reported the prevalence of migraine ranging from 12.2 to $28.1 \%$ with a combined prevalence of $18.9 \%$ (6). The prevalence in our study population is consistent with the previous study findings using the same tool in different settings.

The prevalence of migraine was significantly higher among female participants of our study ( $29 \%$ in female and $12 \%$ in male). Migraine was reported as more prevalent among females in many of the previous studies (26-28). However, some studies reported no significant difference between males and females $(29,30)$. This gender difference in a conservative setting like Bangladesh needs further exploration. According to our findings, participants from the higher socioeconomic conditions were more likely to suffer from migraines (27\%). This finding is contradictory with the social causation hypothesis of migraine as most of the previous studies reported lower socioeconomic conditions as a risk factor of migraine (31-34). Further investigations using a well-established clinician-administered diagnostic tool may resolve the ambiguity.

Among the lifestyle-related factors, infrequent exercise (moderate exercise for at least 30 minutes for less than three days a week) and higher screen time ( $>6$ hours) were associated with migraine. However, regular exercise (3 or more days a week) was not associated with migraine in logistic regression in our study. Though irregular exercise can trigger migraine attacks, there are pieces of evidence that regular exercise may have a prophylactic effect on migraine frequency which is most probably due to an altered migraine triggering threshold in persons who exercise regularly (35-37). Similar to our findings, higher screen time showed a positive association with migraine prevalence in some previous studies $(38,39)$. Other lifestyle-related factors such as tobacco smoking and substance abuse which have been reported as risk factors of migraines in previous studies (40-42) were not found to be associated with migraines in our study.

Symptoms of anxiety and depression were significantly associated with migraine among our study population. The risk of having migraines was more among the participants with anxiety compared to those with depressive symptoms, which is consistent with a previous finding (43). There are a number of existing evidence supporting the association between migraine and psychological distress (44-46). However, due to the cross-sectional nature of the study, the relation between migraine and psychological distress remained ambiguous.

Elevated stress level, regular sleep disturbance, academic pressure and external noise were the most frequently reported triggers of migraine among our participants, which is consistent with the finding of a review article including 25 studies where these particular factors were enlisted among the top ten triggering factors of migraine (5). One-third of the participants with migraines reported more than ten attacks of migraines during the past month and almost similar percentages of them reported severe headaches during the attacks. This high rate of frequency and intensity of headache during the migraine attacks caused severe migraine-related disability of more than $37 \%$ of the migraineurs as measured by the HIT-6 scale. This finding is consistent with the findings of some previous studies conducted using the 
same scale or the MIDAS scale $(47,48)$, though some other studies reported a higher rate of severe disability compared to our findings $(49,50)$.

\section{Strengths And Limitations}

The present study provides baseline information about the prevalence, associated factors, and day-to-day impact of migraine among the university students of Bangladesh. We anticipate that the findings will be somehow helpful for understanding the epidemiology of migraines among students in this country and guide further research on the migraineurs. However, some limitations of the study would be worth mentioning. Firstly, the study was conducted in a specific cohort of the population (university students), so the findings cannot be inferential for the overall population. Moreover, an online survey had a potential risk of sampling bias, which could influence the accuracy of the findings. Secondly, being a crosssectional study, it had failed to establish any causal relationship between migraine and the dependent variables. And most importantly, we used ID Migraine ${ }^{T M}$, a self-administered screening tool for migraine, which was not clinically diagnostic. Further studies using clinical diagnostic criteria under the supervision of the clinicians is suggested to get a more comprehensive insight into the epidemiology of migraines in Bangladesh.

\section{Conclusions}

Our study shows that the prevalence of migraine among university students of Bangladesh is alarmingly high, especially female students suffer more. Several modifiable factors including lack of exercise, high screen time and symptoms of anxiety and depression are associated with migraines. Frequent migraine attacks and severe intensity of headache cause a substantial level of disability among these young sufferers. Cautious avoidance of the triggering factors through appropriate interventions and prophylactic medication can mitigate the negative impact of migraine as well as improve the quality of life. We suggest further large-scale longitudinal studies using standard clinical diagnostic tools to report nationwide prevalence \& factors associated to understand the epidemiology of migraine among students in Bangladesh.

\section{Abbreviations}

AOR-Adjusted Odds Ratio; CHERRIES- Checklist for Reporting Results of Internet ESurveys; Cl-Confidence interval; GAD- Generalized Anxiety Disorder; HIT- Headache Impact Test; IBM-International Business Machines; ICHD-International Classification of Headache Disorders; MIDAS-Migraine Disability Assessment; PHQ- Patient Health Questionnaire; PSQI- Pittsburgh sleep quality index; RMCH- Rajshahi Medical College \& Hospital; SE- Standard error; SPSS- Statistical Package for the Social Sciences.

\section{Declarations}


The present study was carried out in accordance with the ethical standard of the World Medical Association (i.e., declaration of Helsinki) as well as the guidelines of Institutional research ethics. The formal ethical approval was endorsed by the Ethical Review Committee of Rajshahi Medical College (RMC/ERC/2020-2022/198/178). Participants were well informed about the procedure and purpose of the study, and confidentiality of their information. Electronic informed consent was ensured by each of participants.

\section{Consent for publication:}

Not applicable.

\section{Availability of data and materials:}

Data will be available on request to the corresponding author.

\section{Competing interest:}

The authors declare that they have no competing interest.

\section{Funding:}

The authors have no support or funding to report.

\section{Author Contributions:}

Conceptualization: Md. Abdur Rafi, Md. Saiful Islam. Formal analysis: Md. Abdur Rafi, Md. Golam Hossain. Investigation: Md. Abdur Rafi, Md. Saiful Islam. Methodology: Md. Abdur Rafi, Md. Saiful Islam, Md. Golam Hossain. Resources: Md. Saiful Islam. Supervision: Md. Golam Hossain. Writing - original draft: Md. Abdur Rafi, Md. Saiful Islam. Writing - review and editing: Md. Abdur Rafi, Md. Saiful Islam, M. Tasdik Hasan, Md. Golam Hossain.

\section{Acknowledgments:}

The authors would like to thank all of the participants who enrolled in this survey willing. Especially, the authors express their profound gratitude to Jakia Akter, Rupa Akter, Mostakima Tawrin, Sadia Jahan, Anika Tahsin Barnana, Ummay Habiba Shorna, Mahmudul Hasan Taqy, Tasmim Hoq, Nadia Akter, Arif Hasan Shakib, Muntaha Binte Alam, Tanjina Yousuf, Tarif Ibne Kamal, Sadia Sristy, Zahid Hasan Rocky, Kifyat Tasnim, Muhammad Bahauddin Kabir, Badrun Nahar Laxy, Mahmud Syed, Md Nahid Hassan, Md. 
Sarowar Jahan, Md Jabed Hossain, Nazmun Nahar Prity, Navid Mahmood Khan, Farhana Yeasmin, Sihab Howladar, Mohammed Emon, Noor Jahan Akter, Reshma Afroz Rimi, Imran Hosen, Md Delwar Hossen, and Md. Rukonozzaman Rukon, for their voluntary contributions during the survey periods.

\section{References}

1. James SL, Abate D, Hassen Abate K, Abay SM, Abbafati C, Abbasi N, et al. Global, regional, and national incidence, prevalence, and years lived with disability for 354 diseases and injuries for 195 countries and territories, 1990â€"2017: a systematic analysis for the Global Burden of Disease Study 2017 [Internet]. 2018 [cited 2020 Sep 16]. Available from: https://github.com/ihmeuw/

2. Leonardi M, Raggi A. Burden of migraine: International perspectives. Neurol Sci. 2013 May 22;34(SUPPL. 1):117-8.

3. Pesa J, Lage MJ. The Medical Costs of Migraine and Comorbid Anxiety and Depression. Headache J Head Face Pain [Internet]. 2004 Jun 4 [cited 2020 Jun 18];44(6):562-70. Available from: https://onlinelibrary.wiley.com/doi/abs/10.1111/j.1526-4610.2004.446004.x

4. Olesen J, Bes A, Kunkel R, Lance JW, Nappi G, Pfaffenrath V, et al. The International Classification of Headache Disorders, 3rd edition (beta version). Cephalalgia [Internet]. 2013 Jul 1 [cited 2020 Sep 16];33(9):629-808. Available from: https://pubmed.ncbi.nlm.nih.gov/23771276/

5. Peroutka SJ. What Turns on a Migraine? A Systematic Review of Migraine Precipitating Factors [Internet]. Vol. 18, Current Pain and Headache Reports. Current Medicine Group LLC 1; 2014 [cited 2020 Sep 16]. p. 454. Available from: http://link.springer.com/10.1007/s11916-014-0454-z

6. Wang X, Zhou HB, Sun JM, Xing YH, Zhu YL, Zhao YS. The prevalence of migraine in university students: A systematic review and meta-analysis [Internet]. Vol. 23, European Journal of Neurology. Blackwell Publishing Ltd; 2016 [cited 2020 Sep 16]. p. 464-75. Available from: https://onlinelibrary.wiley.com/doi/abs/10.1111/ene.12784

7. Al-Hashel JY, Ahmed SF, Alroughani R, Goadsby PJ. Migraine among medical students in Kuwait University. J Headache Pain. 2014 Dec 1;15(1):1-6.

8. Menon B, Kinnera N. Prevalence and characteristics of migraine in medical students and its impact on their daily activities. Ann Indian Acad Neurol. 2013 Apr;16(2):221-5.

9. Perveen I, Parvin R, Saha M, Bari MS, Huda MN, Ghosh MK. Prevalence of Irritable Bowel Syndrome (IBS), Migraine and Co-Existing IBS-Migraine in Medical Students. J Clin DIAGNOSTIC Res. 2016;10(11):0C09.

10. Ray B, Paul N, Hazra A, Das S, Ghosal M, Misra A, et al. Prevalence, burden, and risk factors of migraine: A community-based study from Eastern India. Neurol India [Internet]. 2017 Nov 1 [cited 2020 Sep 15];65(6):1280. Available from: http://www.neurologyindia.com/text.asp? 2017/65/6/1280/217979

11. Eysenbach G. Improving the quality of web surveys: The Checklist for Reporting Results of Internet ESurveys (CHERRIES) [Internet]. Vol. 6, Journal of Medical Internet Research. Journal of Medical 
Internet Research; 2004 [cited 2020 Jul 19]. Available from: /pmc/articles/PMC1550605/? report=abstract

12. Mollayeva T, Thurairajah P, Burton K, Mollayeva S, Shapiro CM, Colantonio A. The Pittsburgh sleep quality index as a screening tool for sleep dysfunction in clinical and non-clinical samples: A systematic review and meta-analysis. Vol. 25, Sleep Medicine Reviews. W.B. Saunders Ltd; 2016. p. 52-73.

13. Lipton RB, Dodick D, Sadovsky R, Kolodner K, Endicott J, Hettiarachchi J, et al. A self-administered screener for migraine in primary care: The ID migraine ${ }^{T M}$ validation study. Neurology [Internet]. 2003 Aug 12 [cited 2020 Jun 25];61(3):375-82. Available from: https://n.neurology.org/content/61/3/375

14. Cousins G, Hijazze S, Van De Laar FA, Fahey T. Diagnostic accuracy of the ID migraine: A systematic review and meta-analysis. Vol. 51, Headache. 2011. p. 1140-8.

15. Tfelt-Hansen P, Pascual J, Ramadan N, Dahlöf C, D’Amico D, Diener H-C, et al. Guidelines for controlled trials of drugs in migraine: third edition. A guide for investigators. Cephalalgia. 2012 Jan;32(1):6-38.

16. Kosinski M, Bayliss MS, Bjorner JB, Ware JEJ, Garber WH, Batenhorst A, et al. A six-item short-form survey for measuring headache impact: The HIT-6. Qual Life Res. 2003 Dec;12(8):963-74.

17. Yang M, Rendas-Baum R, Varon SF, Kosinski M. Validation of the Headache Impact Test (HIT- $\left.6^{T M}\right)$ across episodic and chronic migraine. Cephalalgia [Internet]. 2011 Mar [cited 2020 Sep 15];31(3):357-67. Available from: /pmc/articles/PMC3057423/?report=abstract

18. Spitzer RL, Kroenke K, Williams JBW. Validation and utility of a self-report version of PRIME-MD: The PHQ Primary Care Study. J Am Med Assoc [Internet]. 1999 Nov 10 [cited 2020 Sep 15];282(18):173744. Available from: https://pubmed.ncbi.nlm.nih.gov/10568646/

19. Islam S, Akter R, Sikder T, Griffiths MD. Prevalence and factors associated with depression and anxiety among first-year university students in Bangladesh: A cross-sectional study. Int $\mathrm{J}$ Ment Health Addict. 2020;

20. Islam MS, Rahman ME, Moonajilin MS, Griffiths MD. Validation and evaluation of the psychometric properties of bangla nine-item Internet Disorder Scale-Short Form. J Addict Dis. 2020 Aug;1-10.

21. Kroenke K, Spitzer RL, Williams JBW. The PHQ-9: Validity of a brief depression severity measure. J Gen Intern Med. 2001;16(9):606-13.

22. Spitzer RL, Kroenke K, Williams JBW, Löwe B. A brief measure for assessing generalized anxiety disorder: The GAD-7. Arch Intern Med [Internet]. 2006 May 22 [cited 2020 Sep 15];166(10):1092-7. Available from: https://pubmed.ncbi.nlm.nih.gov/16717171/

23. Islam MS, Ferdous MZ, Potenza MN. Panic and generalized anxiety during the COVID-19 pandemic among Bangladeshi people: An online pilot survey early in the outbreak. J Affect Disord. 2020;276:30-7.

24. Moonajilin MS, Rahman ME, Islam MS. Relationship between overweight/obesity and mental health disorders among Bangladeshi adolescents: A cross-sectional survey. Obes Med. 2020;18:100216. 
25. Chan YH. Biostatistics 202: Logistic regression analysis. Vol. 45, Singapore Med J. 2004.

26. Seifert T, Sufrinko A, Cowan R, Scott Black W, Watson D, Edwards B, et al. Comprehensive Headache Experience in Collegiate Student-Athletes: An Initial Report From the NCAA Headache Task Force. Headache [Internet]. 2017 Jun 1 [cited 2020 Sep 21];57(6):877-86. Available from: https://pubmed.ncbi.nlm.nih.gov/28480575/

27. Birru EM, Abay Z, Abdelwuhab M, Basazn A, Sirak B, Teni FS. Management of headache and associated factors among undergraduate medicine and health science students of University of Gondar, North West Ethiopia. J Headache Pain. 2016 Dec 1;17(1).

28. Lebedeva ER, Kobzeva NR, Gilev D V., Olesen J. Factors Associated with Primary Headache According to Diagnosis, Sex, and Social Group. Headache [Internet]. 2016 Feb 1 [cited 2020 Sep 21];56(2):341-56. Available from: https://pubmed.ncbi.nlm.nih.gov/26833220/

29. Wang X, Sun J, Xing Y, Zhou H, Zhao Y, Zhu Y. The Prevalence and Awareness of Migraine Among University Students in Harbin, China. J Oral Facial Pain Headache [Internet]. 2015 Oct [cited 2020 Sep 21];29(4):384-9. Available from: https://pubmed.ncbi.nlm.nih.gov/26485386/

30. Yu S, Liu R, Zhao G, Yang X, Qiao X, Feng J, et al. The prevalence and burden of primary headaches in China: A population-based door-to-door survey. Headache [Internet]. 2012 Apr [cited 2020 Sep 21];52(4):582-91. Available from: https://pubmed.ncbi.nlm.nih.gov/22590713/

31. Stewart WF, Roy J, Lipton RB. Migraine prevalence, socioeconomic status, and social causation. Neurology [Internet]. 2013 Sep 10 [cited 2020 Sep 22];81(11):948-55. Available from: https://n.neurology.org/content/81/11/948

32. Bigal ME, Lipton RB, Winner P, Reed ML, Diamond S, Stewart WF. Migraine in adolescents: Association with socioeconomic status and family history. Neurology [Internet]. 2007 Jul 3 [cited 2020 Sep 22];69(1):16-25. Available from: https://n.neurology.org/content/69/1/16

33. Gu X, Xie YJ. Migraine attacks among medical students in Soochow university, southeast China: A cross-sectional study. J Pain Res [Internet]. 2018 Apr 12 [cited 2020 Sep 22];11:771-81. Available from: https://pubmed.ncbi.nlm.nih.gov/29695929/

34. Winter AC, Berger K, Buring JE, Kurth T. Associations of socioeconomic status with migraine and nonmigraine headache. Cephalalgia [Internet]. 2012 Jan 15 [cited 2020 Sep 22];32(2):159-70. Available from: http://journals.sagepub.com/doi/10.1177/0333102411430854

35. Amin FM, Aristeidou S, Baraldi C, Czapinska-Ciepiela EK, Ariadni DD, Di Lenola D, et al. The association between migraine and physical exercise [Internet]. Vol. 19, The journal of headache and pain. BioMed Central; 2018 [cited 2020 Sep 22]. p. 83. Available from: https://doi.org/10.1186/s10194-018-0902-y

36. Ahn AH. Why does increased exercise decrease migraine? Curr Pain Headache Rep [Internet]. 2013 Dec 5 [cited 2020 Sep 22];17(12):1-4. Available from: https://link.springer.com/article/10.1007/s11916-013-0379-y

37. Daenen L, Varkey E, Kellmann M, Nijs J. Exercise, Not to Exercise, or How to Exercise in Patients With Chronic Pain? Applying Science to Practice. Clin J Pain [Internet]. 2015 Feb 21 [cited 2020 Sep 
22];31(2):108-14. Available from: http://journals.Iww.com/00002508-201502000-00003

38. Malkki H. Migraine: Long screen time exposure could increase the risk of migraine [Internet]. Vol. 12, Nature Reviews Neurology. Nature Publishing Group; 2016 [cited 2020 Sep 22]. p. 4. Available from: http://dx.doi.org/10.1177/0333102415620286

39. Montagni I, Guichard E, Carpenet C, Tzourio C, Kurth T. Screen time exposure and reporting of headaches in young adults: A cross-sectional study. Cephalalgia [Internet]. 2016 Oct 1 [cited 2020 Sep 22];36(11):1020-7. Available from: http://journals.sagepub.com/doi/10.1177/0333102415620286

40. Panconesi A. Alcohol and migraine: Trigger factor, consumption, mechanisms. A review [Internet]. Vol. 9, Journal of Headache and Pain. BioMed Central; 2008 [cited 2020 Sep 22]. p. 19-27. Available from: https://thejournalofheadacheandpain.biomedcentral.com/articles/10.1007/s10194-008-00061

41. Rozen TD. A History of Cigarette Smoking Is Associated With the Development of Cranial Autonomic Symptoms With Migraine Headaches. Headache J Head Face Pain [Internet]. 2011 Jan 1 [cited 2020 Sep 22];51(1):85-91. Available from: http://doi.wiley.com/10.1111/j.1526-4610.2010.01707.x

42. Aamodt AH, Stovner LJ, Hagen K, Bråthen G, Zwart J. Headache prevalence related to smoking and alcohol use. The Head-HUNT Study. Eur J Neurol [Internet]. 2006 Nov 1 [cited 2020 Sep 22];13(11):1233-8. Available from: http://doi.wiley.com/10.1111/j.1468-1331.2006.01492.x

43. Peres MFP, Mercante JPP, Tobo PR, Kamei H, Bigal ME. Anxiety and depression symptoms and migraine: a symptom-based approach research. J Headache Pain [Internet]. 2017 Dec 1 [cited 2020 Sep 24];18(1). Available from: https://pubmed.ncbi.nlm.nih.gov/28324317/

44. Minen MT, De Dhaem OB, Van Diest AK, Powers S, Schwedt TJ, Lipton R, et al. Migraine and its psychiatric comorbidities [Internet]. Vol. 87, Journal of Neurology, Neurosurgery and Psychiatry. BMJ Publishing Group; 2016 [cited 2020 Sep 24]. p. 741-9. Available from: https://pubmed.ncbi.nlm.nih.gov/26733600/

45. Song TJ, Cho SJ, Kim WJ, Yang KI, Yun CH, Chu MK. Anxiety and depression in probable migraine: A population-based study. Cephalalgia [Internet]. 2017 Aug 1 [cited 2020 Sep 24];37(9):845-54. Available from: https://pubmed.ncbi.nlm.nih.gov/27250234/

46. Demir UF, Bozkurt O. Effects of Perceived Social Support, Depression and Anxiety Levels on Migraine. Arch Neuropsychiatry [Internet]. 2020 Apr 20 [cited 2020 Sep 24];57(3). Available from: https://pubmed.ncbi.nlm.nih.gov/32952423/

47. Shin HE, Jeong ; Park W, Yeong „ Kim I, Kwang ; et al. Headache Impact Test-6 (HIT-6) Scores for Migraine Patients: Their Relation to Disability as Measured from a Headache Diary. J Clin Neurol [Internet]. 2008 [cited 2020 Sep 24];4:158-63. Available from: www.headachetest.com/HIT6translations.html

48. Goldstein ED, Badi MK, Klaas JP, Glover P, Rozen TD, Huang JF, et al. A Cross-Sectional Analysis of Migraine-Related Disability in CADASIL: A Mayo Clinic Cohort. Neurologist [Internet]. 2019 Nov 1 [cited 2020 Sep 24];24(6):161-4. Available from: https://pubmed.ncbi.nlm.nih.gov/31688705/ 
49. Alemayehu Ayele B, Mamushet Yifru Y. Migraine-related disability and co-morbid depression among migraineurs in Ethiopia: a cross-sectional study. [cited 2020 Sep 24]; Available from: https://doi.org/10.1186/s12883-018-1095-3

50. Yang M, Rendas-Baum R, Varon SF, Kosinski M. Validation of the Headache Impact Test (HIT- $\left.6^{T M}\right)$ across episodic and chronic migraine. Cephalalgia [Internet]. 2011 Mar 6 [cited 2020 Sep 24];31(3):357-67. Available from: http://journals.sagepub.com/doi/10.1177/0333102410379890

\section{Figures}

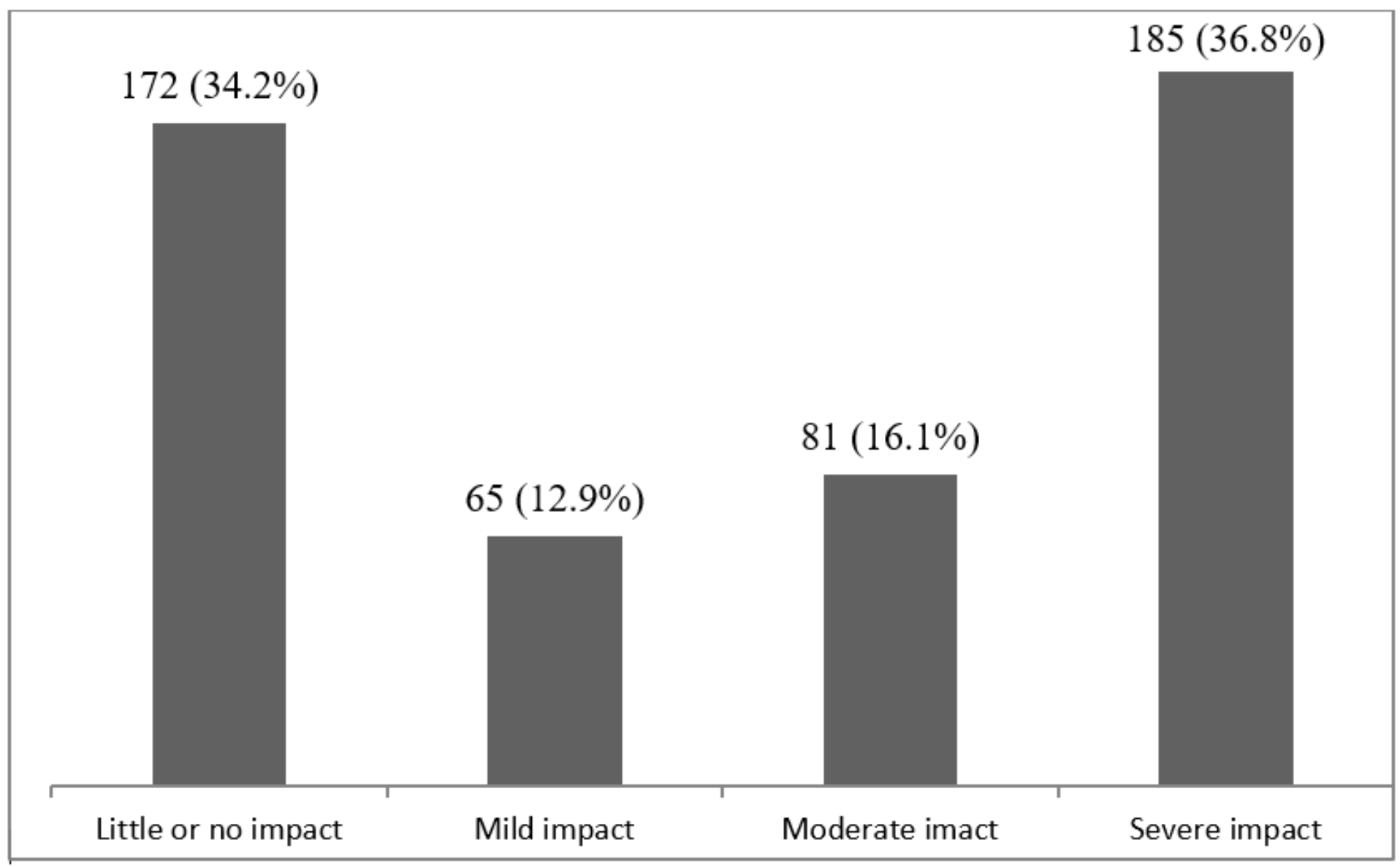

\section{Figure 1}

Impact of migraine among the participants $(n=503)$ 




Figure 1

Impact of migraine among the participants $(n=503)$ 